\title{
Adsorption of humic acid from aqueous solutions onto shellfish ash: Kinetic and isotherm studies and artificial neural network modeling
}

\author{
Behzad Jamshidi ${ }^{1,2,3}$, Yaser Tahmasebi Birgani ${ }^{1,4}$, Sahand Jorfi ${ }^{1,4}{ }^{\circledR}$, Afshin Takdastan ${ }^{1,4}{ }^{\circledR}$, Mahboobeh \\ Dehvari $^{1,2^{*}}{ }^{(\mathbb{D}}$, Behnam Jamshidi $^{(\mathbb{D}}$
}

${ }^{1}$ Department of Environmental Health Engineering, Faculty of Public Health, Ahvaz Jundishapur University of Medical Sciences, Ahvaz, Iran

${ }^{2}$ Student Research Committee, Faculty of Public Health, Ahvaz Jundishapur University of Medical Sciences, Ahvaz, Iran ${ }^{3}$ Department of Environmental Health Engineering, Petroleum Industry Health Organization, NIOC, Ahvaz, Iran

${ }^{4}$ Environmental Technologies Research Center, Faculty of Public Health, Ahvaz Jundishapur University of Medical Sciences, Ahvaz, Iran

${ }^{5}$ Department of Environmental Engineering, Faculty of Environment and Natural Resources, Malayer University, Malayer, Iran

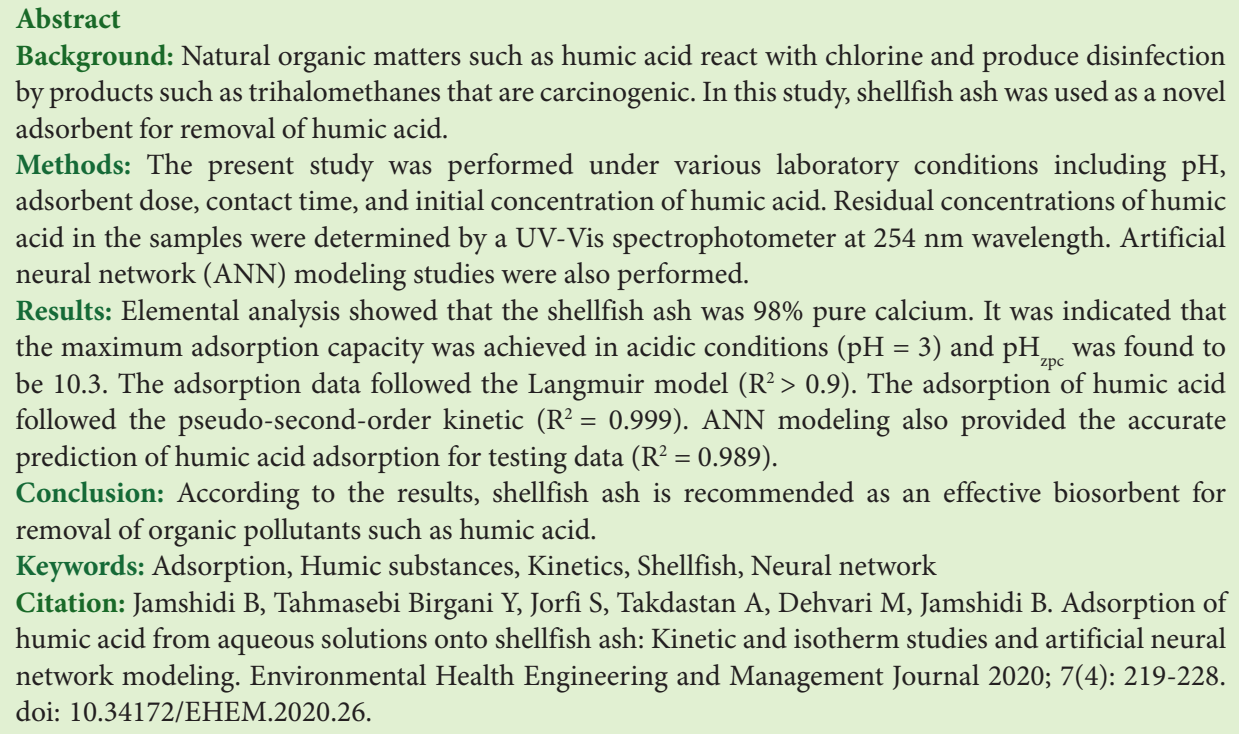

\section{Article History:}

Received: 13 July 2020

Accepted: 11 October 2020

ePublished: 13 November 2020

\section{Introduction}

Humic substances are the most widespread natural organic matter on the Earth (1) that are present in soils, surface and ground waters. They can be classified as humin, humic acids (HAs), and fulvic acids based on their solubility under acidic or alkaline conditions (2). HA is formed by the breakdown of animal and vegetable matter in the environment (3).

HA can affect water quality adversely through constituting a yellow color in drinking water but the most important problems caused by these materials include binding with metal ions to increase their concentrations exceeding the acceptable limits (1), reaction with chlorine during drinking water treatment, and production of disinfection byproducts, such as trihalomethanes that are classified as carcinogenic compounds (1,3-5).

Hence, removal of HA from aqueous solutions is essential (3). For this purpose, various methods such as chemical coagulation (6), membrane separation, advanced oxidation (7), adsorption (3), and ozonation have been used (8-11). The conventional methods used for water treatment cannot be efficient enough to achieve the favorable degree of HA removal. These techniques have also some disadvantages like high costs, high energy consumption, and incomplete removal (4). As a result, cost-effective, effective, and environmentally friendly methods have been developed. So that researchers pay considerable attention to the absorption process (3). 
Various adsorbents, such as activated carbon (12), pillared bentonite (13), chitosan- $\mathrm{H}_{2} \mathrm{SO}_{4}$ beads (14), aminopropylfunctionalized rice husk ash (RHA) (15), and natural zeolite (16), have been tested for HA removal. Activated carbon as a porous material is a popular adsorbent for removal of pollutants from water, but it is not effective in the removal of large molecules such as HA because it cannot penetrate the pores (17). In addition, the adsorbent is still expensive and has high regeneration cost (12). Therefore, there is a growing interest in the application of low-cost adsorbents. Different adsorbents such as fly ash and biomass have been studied to remove HA (17).

In comparison with activated carbon, waste shellfish is relatively cheap due to its accessibility and abundance. However, the capacity of material derived from waste shellfish to adsorb HA has not been tested previously. The aim of the present study was to evaluate shellfish ash as a new and low-cost adsorbent for removal of HA from aqueous solutions and the effect of various variables including $\mathrm{pH}$, adsorbent dose, contact time, initial concentration of HA on the absorption efficiency to offer this adsorbent as an alternative for the existing commercial materials. Also, adsorption isotherms and kinetics were investigated.

Another aim of the study was to evaluate the use of artificial neural network (ANN) model to predict the HA removal by shellfish. ANN is a numerical estimation technique, which is used to find nonlinear relationships between input and output variables $(18,19)$. ANNs apply the same process as the human brain's nervous system (1921). Neural networks have been widely applied in a variety of topics such as modeling of wastewater treatment plants (22), predicting river water quality (23), and modeling of pollutants adsorption processes $(24,25)$. There are several types of network architecture, among which the feedforward network or multilayer perceptron (MLP) is the most common network (21). In this study, the MLP network due to its public and simple structure was used.

\section{Materials and Methods}

\section{Materials}

The HA used in this study was purchased from Aldrich Company. Other chemicals were of analytical grade and were purchased from Merck, Germany.

\section{Preparation of humic acid solution}

A stock solution of HA (1000 mg/L) was prepared by dissolving $1.00 \mathrm{~g}$ of HA powder purchased from SigmaAldrich in $1 \mathrm{~L}$ of distilled water. A few drops of $\mathrm{NaOH}$ solution $(1.00 \mathrm{~N})$ were also added to complete the dissolving of HA. To prepare various concentrations of $\mathrm{HA}$, the stock solution was diluted with distilled water.

\section{Preparation of biosorbent}

Shellfishes were collected from Bandar Abbas city, coastal area of Persian Gulf locality, south of
Iran. The collected shellfishes were washed with distilled water to remove impurities, and then, were sun-dried. Shellfishes were converted to ash by an electric oven at temperature of $400^{\circ} \mathrm{C}$ for 2 hours. The adsorbent was pulverized using standard ASTM sieves (40 to 60 meshes).

\section{Characterization of shell ash powder}

After preparation of the adsorbent according to the above-mentioned method, the surface morphology of the adsorbent was done by the scanning electron microscope (SEM, SERON, AIS-2100, South Korea) operated at a 20 $\mathrm{kV}$ accelerating potential. For this purpose, shellfish ash powder was deposited on conductive glue and coated with a thin layer of gold, before the formation of SEM images. The X-ray diffraction analysis of the shellfish ash was performed by the Bruker X-ray diffractometer (Germany).

\section{Determination of shellfish ash $\mathrm{pH}_{z p c}$}

$\mathrm{pH}_{z p c}$ is an important characteristic of any adsorbent, which indicates the electrical neutrality of the adsorbent surface at certain $\mathrm{pH}$ values. To determine the $\mathrm{pH}_{\mathrm{zpc}}, 100$ $\mathrm{mL}$ of $0.01 \mathrm{M} \mathrm{NaCl}$ solution which its $\mathrm{pH}$ was adjusted between 3-12, was transferred to a conical flask, and then, $0.40 \mathrm{~g}$ of the adsorbent was added. After $48 \mathrm{~h}$, the final $\mathrm{pH}$ of the solutions was measured by a $\mathrm{pH}$ meter (Wagtech Mi 151, USA). Then, graphs were plotted as $\mathrm{pH}_{\text {final }}$ versus $\mathrm{pH}_{\text {initial }}$. The intersection point of the two curves was recorded as the $\mathrm{pH}_{\mathrm{zpc}}$ of shellfish ash.

\section{Humic acid detection}

The absorbance of HA was obtained before and after adsorption at the maximum wavelength of $254 \mathrm{~nm}$ using a UV-vis spectrophotometer (UV/Visible SP-3000 PlusJapan). The remaining concentration was calculated by the standard curve equation of spectrophotometer.

\section{Experimental procedure}

The experiments were performed at $\mathrm{HA}$ initial concentrations of 25 and $50 \mathrm{mg} / \mathrm{L}$, adsorbent dose of 0.05 $0.4 \mathrm{~g} / 100 \mathrm{~mL}$, contact time of 20-180 $\mathrm{min}$, and $\mathrm{pH}$ of 3-12. To design the experiments, one-factor-at-a-time method was applied. So that by keeping several variables constant, one variable was examined.

Mixing was performed using a mechanical shaker (INNOVA 40R, England) at $150 \mathrm{rpm}$. Then, samples were filtered using a $0.2 \mu \mathrm{m}$ filter (Sartorius, Germany) before analysis. The adsorption capacity $\left(\mathrm{q}_{\mathrm{e}}, \mathrm{mg} / \mathrm{g}\right)$ and the removal efficiency (R\%) was calculated using Eqs. (1) and $(2)(1,26)$ :

$$
\begin{aligned}
& q_{e}=\frac{\left(C_{0}-C_{t}\right) V}{M} \\
& R(\%)=\frac{\left(C_{0}-C_{t}\right)}{C_{0}} \times 100
\end{aligned}
$$

where, $V$ is the volume of solution (L), $M$ is adsorbent 
dosage (g), and $C_{t}$ and $C_{o}$ are the equilibrium and initial HA concentrations $(\mathrm{mg} / \mathrm{L})$, respectively $(1,26)$.

\section{Adsorption isotherms}

The adsorption isotherm is the relationship between the amount of adsorbed pollutant at constant temperature and the equilibrium adsorbate concentration (15). The distribution of HA between the liquid and solid phases can be declared by common isotherm models including Langmuir, Freundlich, and Temkin models (14). In this stage, $0.05-0.4 \mathrm{~g}$ of adsorbent was added to $100 \mathrm{~mL}$ of HA solutions with concentrations of 25 and $50 \mathrm{mg} / \mathrm{L}$. Optimum $\mathrm{pH}$ values and contact time were considered.

The Langmuir isotherm describes monolayer adsorption of pollutant on the adsorbent surface (27). The linear form of Langmuir equation is presented in Eq. (3).

$\frac{1}{q}=\frac{1}{q_{\max }}+\frac{1}{K_{e} q_{\max } C}$

where $q$ and $q_{\max }$ are the amount of adsorbed HA $(\mathrm{mg} / \mathrm{g})$ and the maximum adsorption capacity $(\mathrm{mg} / \mathrm{g})$, respectively. $K_{e}$ is the Langmuir adsorption constant (L/ $\mathrm{mg}$ ) and $C$ is the HA equilibrium concentration $(\mathrm{mg} / \mathrm{L})$ (28).

If plot of 1 /q versus $1 / \mathrm{C}$ is a direct line, then, the Langmuir equation complies with the adsorption equilibrium. The slope and intercept of this line represents the amounts of constants $\mathrm{q}_{\max }$ and $\mathrm{K}_{\mathrm{a}}$, respectively (29). The important parameter of Langmuir isotherm is $R_{L}$, a dimensionless constant that is called equilibrium parameter and calculated by Eq. (4) (29).

$$
R_{L}=\frac{1}{1+b C_{0}}
$$

where $C_{0}$ is the HA initial concentration and $b$ is the Langmuir constant (28). The separation factor $\left(\mathrm{R}_{\mathrm{L}}\right)$ indicates whether the adsorption is favorable or not. This factor is classified as irreversible $\left(\mathrm{R}_{\mathrm{L}}=0\right)$, linear $\left(\mathrm{R}_{\mathrm{L}}=1\right)$, unfavorable $\left(\mathrm{R}_{\mathrm{L}}>1\right)$, and favorable $\left(0<\mathrm{R}_{\mathrm{L}}<1\right)(28,30)$.

The Freundlich isotherm model is applicable to multilayer adsorption and adsorption on a heterogeneous surface. The linear form of the isotherm has been given in Eq. (5) (5).

$$
L n q_{e}=\operatorname{Ln} K_{f}+\frac{1}{n} \operatorname{Ln} C_{e}
$$

where $q_{e}$ is the amount of HA adsorbed per unit mass of adsorbent $(\mathrm{mg} / \mathrm{g}), K_{f}$ is the adsorption capacity $(\mathrm{mg} / \mathrm{g}), C_{e}$ is the solute concentration $(\mathrm{mg} / \mathrm{L})$, and $n$ is the adsorption intensity (g/L) (31).

The Temkin isotherm equation expresses adsorbentadsorbate interactions. This isotherm assumes that the adsorption (a function of temperature) decreases logarithmically with coverage linearly (32). The Temkin isotherm equation is presented as Eq. (6):

$$
q_{e}=B_{T} \operatorname{Ln} K_{t}+B_{T} \operatorname{Ln} C_{e}
$$

Where $K_{t}$ is the binding constant which represents the maximum binding energy $(\mathrm{L} / \mathrm{mg})$ and $B_{T}$ is related to the heat of adsorption $(\mathrm{kJ} / \mathrm{mol})(31) . \mathrm{K}_{\mathrm{t}}$ and $\mathrm{B}_{\mathrm{T}}$ parameters are calculated based on the slope and intercept of the plot of $\mathrm{q}_{\mathrm{e}}$ against $\ln C_{\mathrm{e}}$, respectively $(28,32,33)$.

\section{Adsorption kinetics}

To further study the adsorption mechanism of HA using shellfish ash and rate-controlling steps, kinetic studies were performed. In this study, adsorption kinetics of pseudofirst-order and pseudo-second-order were investigated. To perform kinetic tests, the HA concentration was 25 and $50 \mathrm{mg} / \mathrm{L}$, and $0.4 \mathrm{~g}$ of the adsorbent was added to $100 \mathrm{~mL}$ of HA solution. In this stage, the optimum $\mathrm{pH}$ obtained from the previous steps was considered. The experiments related to the adsorption kinetics was done at different time intervals (20-180 minutes and 24 hours).

The pseudo-first-order equation has been used for the adsorption of pollutant on the adsorbent surface (34). Its linear form is presented in Eq. (7):

$$
\operatorname{Ln}\left(q_{e}-q_{t}\right)=\operatorname{Ln} q_{e}-K_{1} t
$$

Where $k_{1}$ is the rate constant in the pseudo-first-order (1/ $\min ) . q_{e}$ and $q_{t}$ are the adsorption equilibrium capacity $(\mathrm{mg} / \mathrm{g})$ and the amount of HA adsorbed at time $t(\mathrm{mg} / \mathrm{g})$, respectively (31). The constant and adsorption capacity were determined by plotting of $\ln \left(\mathrm{q}_{\mathrm{e}}-\mathrm{q}_{\mathrm{t}}\right)$ versus time $(5,35)$.

The pseudo-second-order model is based on the assumption that the adsorption follows chemisorptions $(31,34)$. Its linear form is described by Eq. (8):

$$
\frac{t}{q_{t}}=\frac{1}{K_{2} q_{e}{ }^{2}}+\frac{1}{q_{e}} t
$$

Where $K_{2}$ is the rate constant of pseudo-second-order (g/ $\operatorname{mg} \min ) \cdot \mathrm{q}_{\mathrm{e}}$ and $\mathrm{k}_{2}$ can be calculated by plotting of $\mathrm{t} / \mathrm{q}_{\mathrm{t}}$ versus time.

\section{Artificial neural networks modeling}

ANNs are mathematical models that have been established based on the biological activities of human brain such as learning, thinking, and problem solving (36). Multi-layer perceptron is a supervised learning algorithm with one or more hidden layers. In this study, developed ANN was considered as one input, one hidden, and one output layer. Inputs were separately weighted, and then, summed by a constant value as bias. The data were modified by the activation function and passed to the output $(20,36,37)$. The mathematical expression of neural computation is presented as Eq. (9): 


$$
Y_{j}=f\left(\sum_{i=0}^{i} w_{j} \alpha_{i}+b\right)
$$

Where $\alpha_{i}, w_{i j}$, and $b$ are inputs, weights, and bias, respectively (20). Figure 1 indicates the architecture of ANN with hidden layers.

In order to compare the predicted outputs with experimental ones, weight and bias values were adjusted gradually during the training phase. In this study, ANN was trained by the Levenberg-Marquardt backpropagation algorithm that is more powerful and faster than the other algorithms. Equations (10) and (11) indicate the most transfer functions which are practical for developing the MLP (20):

$$
\begin{aligned}
& \text { Sigmoidal: } f(x)=\frac{1}{\left(1+\exp ^{(-x)}\right)} \\
& \text { Tansig: } f(x)=\frac{2}{\left(1+\exp ^{(-2 x)}\right)}
\end{aligned}
$$

In this study, the experiments were modelled using ANNs. In the architecture of $\mathrm{ANN}$, four parameters including $\mathrm{pH}$, adsorbent dose, HA concentration, and contact time were considered as model inputs to simulate the HA removal efficiency as the output. Neural network performance was then evaluated through mean squared error (MSE) and correlation coefficient ( $\left.\mathrm{R}^{2}\right)$ (Eqs. 12 and 13).

$$
\begin{aligned}
& M S E=\frac{\sum_{i=1}^{n}\left(y_{o b s, i}-y_{\bmod e, i}\right)^{2}}{n}
\end{aligned}
$$

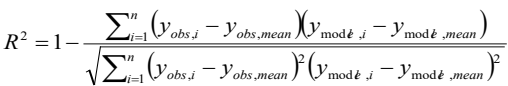

Where $n$ and $i$ are the number and index of data, respectively. $y_{\text {obs, } i}$ and $y_{\text {model }, i}$ are the measured output and the predicted output values by the model, respectively. $y_{\text {obs,mean }}$ and $y_{\text {model,mean }}$ are the average of the experimental measured output and the average of the predicted values by the model, respectively (36).

In the present study, Levenberg-Marquardt backpropagation algorithm was used for network

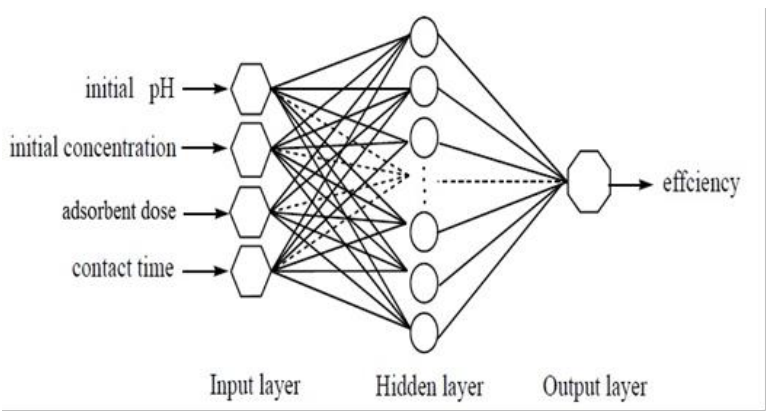

Figure 1. Architecture of neural network system. training. This algorithm accelerates attaining convergence and provides the accuracy of the results (38). The tansigmoid (Eq. 11) and linear transfer functions were used for transfer function in the hidden and output layers.

All samples were normalized between $0-1$, to achieve fast convergence, commensurability of the inputs scale, as well as the minimal RMSE values. The normalized values of data were obtained according to Eq. (14):

$$
X_{i}=\frac{X_{1}-X_{\min }}{X_{\max }-X_{\min }}
$$

Where $X_{\text {min }}, X_{\text {max }}$, and $X_{1}$ are the minimum, maximum, and actual data, respectively (36).

Results

\section{Characterization of shellfish ash powder}

The SEM image of shellfish ash is shown in Figure 2a. As shown in this figure, shellfish ash powder has an irregular surface structure, a situation which favors the adsorption of HA on different parts of the beads. The samples did not show the well-defined pore structures.

The X-ray diffraction (XRD) pattern is displayed in Figure $2 \mathrm{~b}$. Elemental analysis showed that the shellfish ash was $98 \%$ pure calcium $\left(2.60 \mathrm{~A}^{\circ}, 3.40 \mathrm{~A}^{\circ}\right.$, and $\left.3.60 \mathrm{~A}^{\circ}\right)$, which is due to the presence of calcium carbonate in the shellfish structure (35). As shown in the XRD pattern, there are trace amounts of other elements in the adsorbent that is because of some impurities in shells.

$\mathrm{pH}_{z p c}$ of shellfish ash

$\mathrm{pH}_{z \mathrm{pc}}$ plays an important role in characterizing the surface
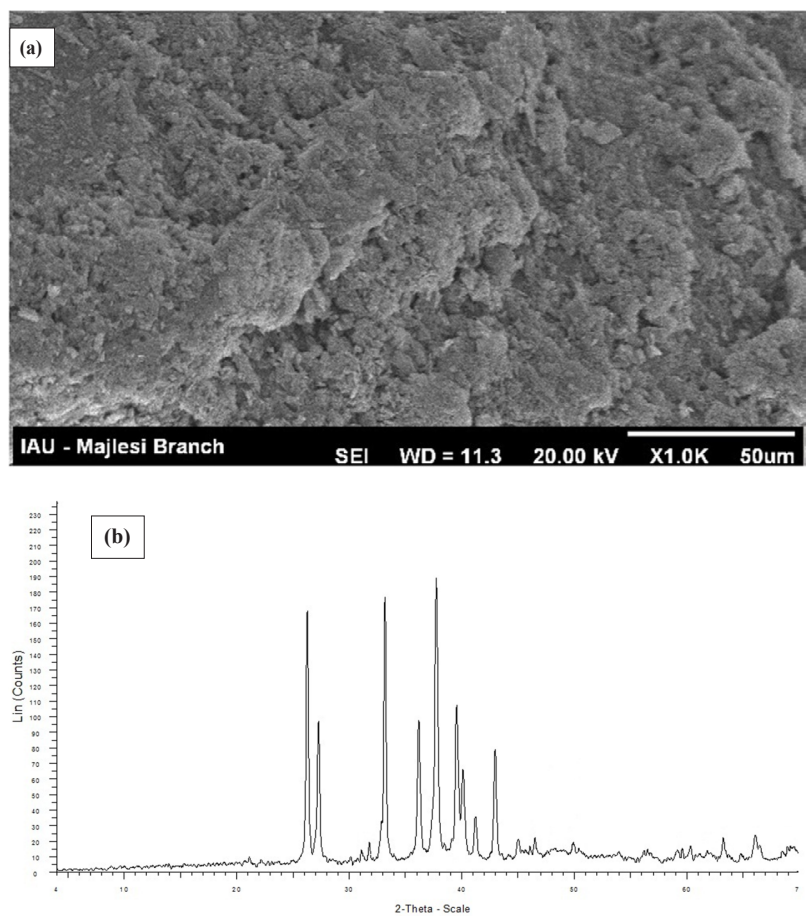

Figure 2. (a) Scanning electron microscope (SEM); (b) X-ray diffraction (XRD) of shellfish ash. 
nature of any adsorbent. The $\mathrm{pH}_{\mathrm{zpc}}$ of shellfish ash was found to be 10.3 (Figure 3).

\section{Effect of $p H$}

The results of $\mathrm{pH}$ effect on the HA removal using shellfish ash under special conditions (temperature $=20^{\circ} \mathrm{C}$ and initial HA concentration $=25 \mathrm{mg} / \mathrm{L}$, adsorbent dose $=$ $0.4 / 100 \mathrm{~mL}$, contact time $=24$ hours) are presented in Figure 4. The results indicated that as $\mathrm{pH}$ increased, the HA removal efficiency decreased. The removal efficiency at pHs of 3 and 12 was equal to $90.96 \%$ and $24.48 \%$, respectively. The adsorption capacity $\left(\mathrm{q}_{\mathrm{e}}\right)$ of HA on the shellfish ash powder decreased by increasing $\mathrm{pH}$ from 3 to 12. So that at $\mathrm{pH}=3$ and $12, \mathrm{q}_{\mathrm{e}}$ was equal to 5.685 and 0.75 $\mathrm{mg} / \mathrm{g}$, respectively (inset of Figure 4).

\section{Effect of adsorbent dose}

The effect of adsorbent dose on the removal efficiency of HA by shellfish ash was investigated at HA initial concentration of $25 \mathrm{mg} / \mathrm{L}, \mathrm{pH}=3$, and contact time of 24 h. The results are shown in Figure 5.

According to the results, by increasing adsorbent dose from 0.05 to $0.4 \mathrm{~g} / 100 \mathrm{~mL}$, the $\mathrm{HA}$ removal efficiency

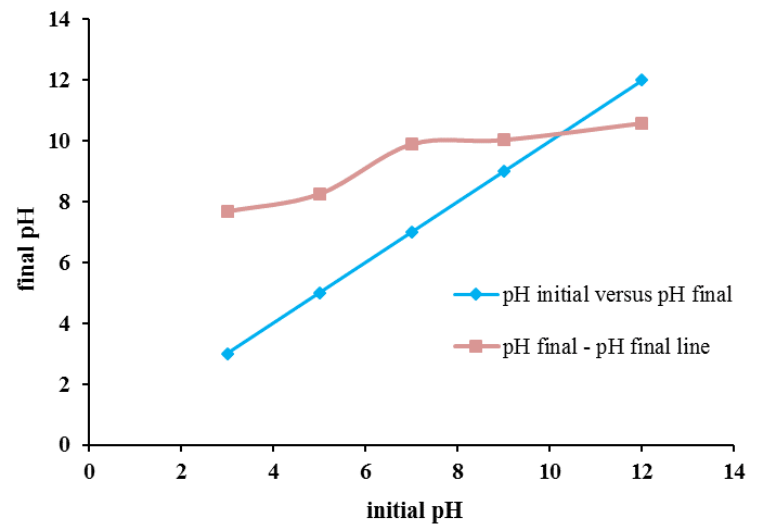

Figure 3. Plot for determination of the adsorbent $\mathrm{pH}_{\mathrm{zpc}}$.

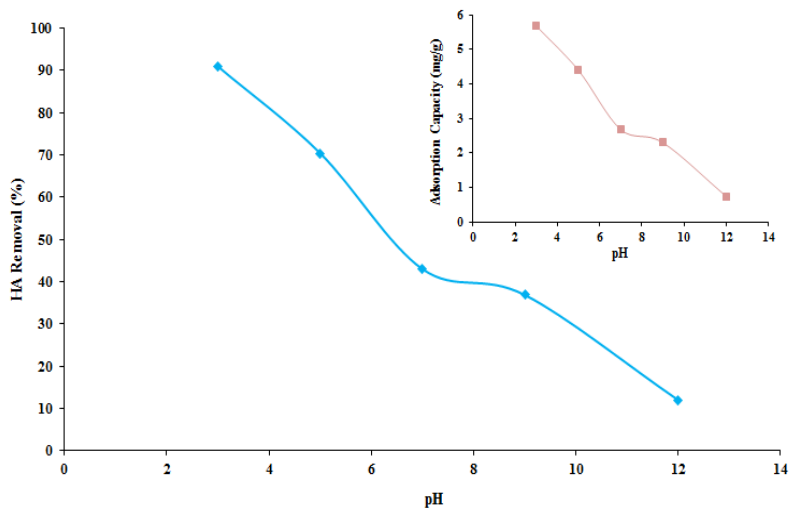

Figure 4. Effect of $\mathrm{pH}$ on humic acid removal, inset: adsorption capacity.

$\left(\mathrm{C}_{\mathrm{HA}}=25 \mathrm{mg} / \mathrm{L}, \mathrm{T}=20^{\circ} \mathrm{C}\right.$, Dose $=0.4 \mathrm{~g} / 100 \mathrm{~mL}$, time $\left.=24 \mathrm{~h}\right)$.

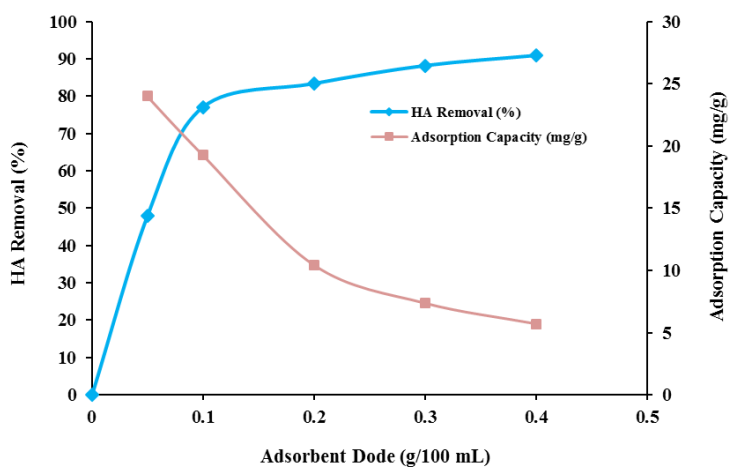

Figure 5. Effect of adsorbent dose on the removal and adsorption capacity of humic acid.

$\left(\mathrm{C}_{\mathrm{HA}}=25 \mathrm{mg} / \mathrm{L}, \mathrm{T}=20^{\circ} \mathrm{C}, \mathrm{pH}=3\right.$, time $\left.=24 \mathrm{~h}\right)$

increased from $48.04 \%$ to $90.96 \%$, respectively. Also, with increasing adsorbent dose from 24.02 to $5.68 \mathrm{mg} / \mathrm{g}$, the adsorption capacity decreased. The optimum adsorbent dose was obtained to be $0.4 \mathrm{~g} / 100 \mathrm{~mL}$.

\section{Effect of contact time}

For experiments related to this stage, HA concentration of $25 \mathrm{mg} / \mathrm{L}$, adsorbent dosage of $0.4 \mathrm{~g} / 100 \mathrm{~mL}, \mathrm{pH}=3$, and contact time of 20-180 min and 24 hours were considered (Figure 6). The results indicated that with increasing contact time, the removal efficiency of HA also increased. The adsorption of HA by shellfish ash reached equilibrium in 180 minutes. The results of experiments showed that the HA removal rate reaching equilibrium within the first 3 hours of adsorption time.

\section{Effect of initial humic acid concentration}

With increasing the initial concentration of HA solution from 10 to $50 \mathrm{mg} / \mathrm{L}$, the adsorption capacity $\left(\mathrm{q}_{\mathrm{e}}\right)$ increased from 2.2 to $11.87 \mathrm{mg} / \mathrm{g}$ (Figure 7), while with increasing the initial concentration of HA from 50 to $100 \mathrm{mg} / \mathrm{L}$, the HA adsorption capacity was slightly increased from 11.87 to $13.01 \mathrm{mg} / \mathrm{g}$.

\section{Adsorption isotherms}

Adsorption isotherms are one of the aspects investigated in evaluating the adsorption process. The parameters of Langmuir, Freundlich, and Temkin isotherm models are presented in Table 1.

The obtained results from Langmuir isotherm are presented in Figure 8 . The $\mathrm{R}_{\mathrm{L}}$ value obtained was less than $1\left(R_{L}=0.001\right.$ and 0.0001$)$, indicating favorable adsorption of HA. In the Freundlich isotherm, the value of $1 / \mathrm{n}$ for the HA initial concentration of $25 \mathrm{mg} / \mathrm{L}$ was less than $1(1 / \mathrm{n}$ $=0.812$ ) but for the HA initial concentration of $50 \mathrm{mg} / \mathrm{L}$, $1 / \mathrm{n}$ was equal to 1.178 , indicating that the adsorption is unfavorable.

The correlation coefficient $\left(\mathrm{R}^{2}\right)$ for Langmuir, Freundlich, and Temkin isotherms are presented in Table 
1. As shown in this table, $\mathrm{R}^{2}$ value of Langmuir isotherm $(0.997,0.928)$ was higher than that of Freundlich $(0.993$, $0.891)$ and Temkin $(0.991,0.773)$ isotherms.

\section{Adsorption kinetics}

The mechanism of absorption is described by the adsorption kinetics. Kinetic constants (q, k, R2) were calculated and are presented in Table 2.

According to Table 2, the correlation coefficient $\left(\mathrm{R}^{2}\right)$ values of pseudo-first-order reaction were 0.845 and 0.906 for the HA initial concentrations of 25 and $50 \mathrm{mg} / \mathrm{L}$, respectively. The theoretical values $\left(\mathrm{q}_{\mathrm{e}, \mathrm{cal}}\right)$ were more lower than the experimental data $\left(\mathrm{q}_{\mathrm{e}, \text { exp }}\right)$, indicating that the adsorption process did not follow the pseudo-first-order kinetic.

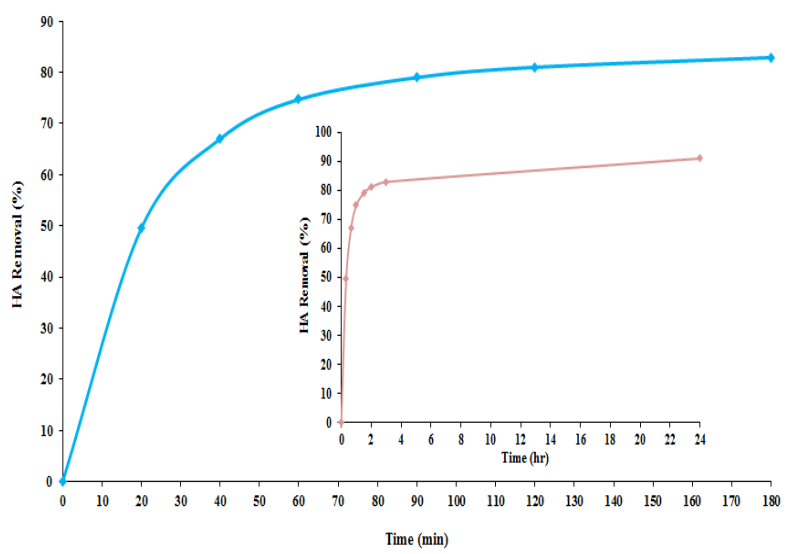

Figure 6. Effect of contact time on the adsorption capacity of humic acid.

$\left(\mathrm{C}_{\mathrm{HA}}=25 \mathrm{mg} / \mathrm{L}, \mathrm{T}=20^{\circ} \mathrm{C}, \mathrm{pH}=3\right.$, Dose $\left.=0.4 \mathrm{~g} / 100 \mathrm{~mL}\right)$.

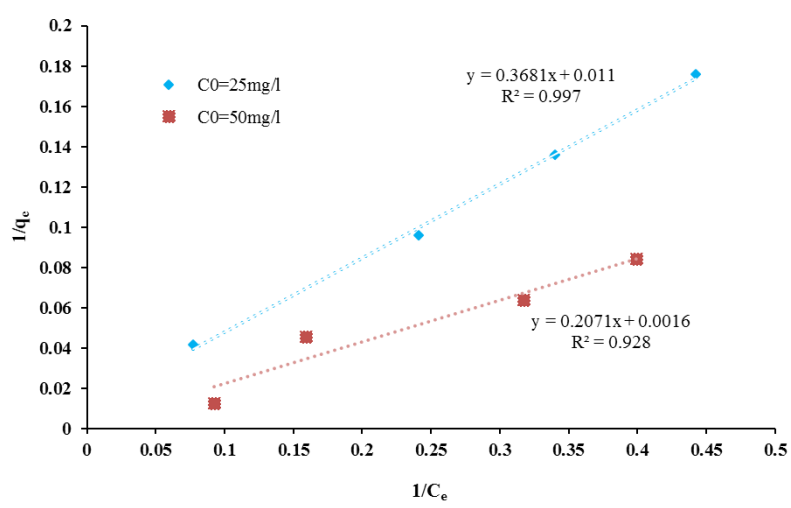

Figure 7. Effect of the HA initial concentration on the adsorption capacity of humic acid.

$\left(\mathrm{pH}=3, \mathrm{~T}=20^{\circ} \mathrm{C}\right.$, Dose $=0.4 \mathrm{~g} / 100 \mathrm{~mL}$, time $\left.=24 \mathrm{~h}\right)$.

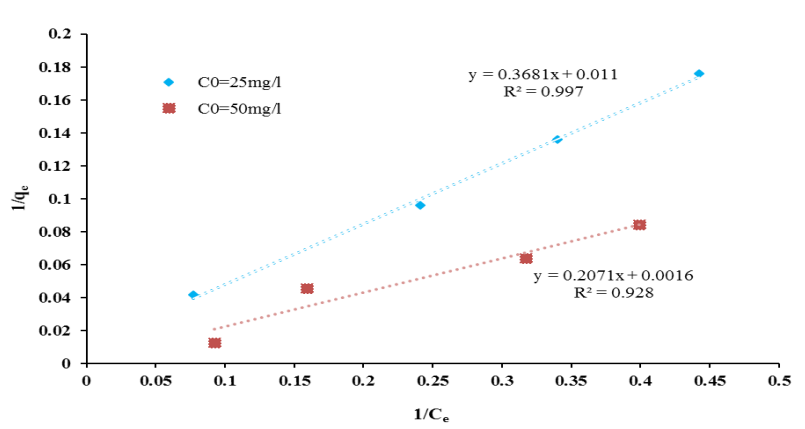

Figure 8. The Langmuir isotherm for humic acid adsorption onto shellfish ash powder.

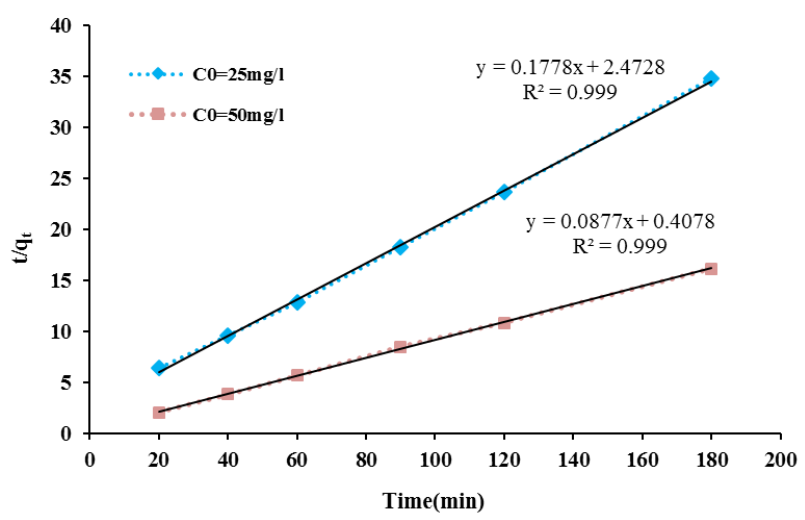

Figure 9. Pseudo-second-order kinetics for humic acid adsorption onto shellfish ash powder.

According to the results (Figure 9), $\mathrm{R}^{2}$ value for the pseudo-second-order was 0.999 for both studied concentrations, which confirms the applicability of the pseudo-second-order equation. Also, there was only a little difference between the $\mathrm{q}_{e^{\prime} \exp }$ and $\mathrm{q}_{\mathrm{e}, \mathrm{al}}$, which amplifies the applicability of this kinetic. According to the obtained results, the adsorption of HA followed the pseudo-secondorder kinetic $\left(\mathrm{R}^{2}>0.99\right)$.

\section{Artificial neural network modeling}

In this study, the tan-sigmoid and linear transfer functions were applied for transfer function in the hidden and output layers. During training, the predicted output was compared with the expected output. To determine the optimal number of neurons in the hidden layer, several neural networks were created with 4 to 20 neurons. The MSE and RMSE for each network were obtained (Figure 10). The neural network model with 6 neurons in the hidden layer had the lowest MSE (17.686) for the test data. Figure 11 indicates a comparison between the predicted

Table 1. Characteristics of adsorption isotherms

\begin{tabular}{|c|c|c|c|c|c|c|c|c|c|c|}
\hline \multirow[b]{2}{*}{ Initial concentration } & \multicolumn{4}{|c|}{ Langmuir isotherm } & \multicolumn{3}{|c|}{ Freundlich isotherm } & \multicolumn{3}{|c|}{ Temkin isotherm } \\
\hline & $\mathbf{k}_{\mathrm{a}}$ & $\begin{array}{c}q_{\max } \\
(\mathrm{L} / \mathrm{mg})\end{array}$ & $\begin{array}{c}R_{\mathrm{L}} \\
(\mathrm{mg} / \mathrm{g})\end{array}$ & $\mathbf{R}^{2}$ & $K_{f}$ & $\begin{array}{c}1 / \mathrm{n} \\
(\mathrm{mg} / \mathrm{g})\end{array}$ & $\mathbf{R}^{2}$ & $\begin{array}{c}K_{t} \\
(L / g)\end{array}$ & $\begin{array}{c}\text { BT } \\
(\mathrm{kJ} / \mathrm{mol})\end{array}$ & $\mathbf{R}^{2}$ \\
\hline $25 \mathrm{mg} / \mathrm{L}$ & 33.45 & 2.71 & 0.001 & 0.997 & 3.06 & 0.812 & 0.993 & 10.76 & 3.956 & 0.991 \\
\hline $50 \mathrm{mg} / \mathrm{L}$ & 207.03 & 4.83 & 0.0001 & 0.928 & 3.713 & 1.178 & 0.891 & 41.08 & 32.71 & 0.773 \\
\hline
\end{tabular}


Table 2. Kinetics constants of humic acid adsorption onto shellfish ash

\begin{tabular}{|c|c|c|c|c|c|c|c|}
\hline \multirow[b]{2}{*}{ Initial concentration } & \multicolumn{4}{|c|}{ Pseudo-first-order } & \multicolumn{3}{|c|}{ Pseudo-second-order } \\
\hline & $\begin{array}{c}q_{e}(\text { calc. })( \\
\mathrm{mg} / \mathrm{g})\end{array}$ & $\begin{array}{c}q_{e}(\text { exp. }) \\
(\mathrm{mg} / \mathrm{g})\end{array}$ & $\begin{array}{c}\mathrm{K}_{1} \\
\left(\min ^{-1}\right)\end{array}$ & $\mathbf{R}^{2}$ & $\underset{(m g / g)}{q_{e}}$ & $\begin{array}{c}\mathrm{K}_{2} \\
\text { (g/mg.min) }\end{array}$ & $\mathbf{R}^{2}$ \\
\hline $25 \mathrm{mg} / \mathrm{L}$ & 2.218 & 5.685 & 0.009 & 0.845 & 5.649 & 0.12 & 0.999 \\
\hline 50 mg/L & 2.214 & 11.873 & 0.006 & 0.906 & 11.494 & 0.18 & 0.999 \\
\hline
\end{tabular}

and experimental values of the output variables with neural network model. The neural network model with 6 neurons in the hidden layer had the highest correlation coefficient $\left(R^{2}=0.989\right)$ for the test data.

\section{Discussion}

\section{Effect of $p H$}

The results of evaluation of $\mathrm{pH}$ effect on the HA adsorption indicated that as $\mathrm{pH}$ increased, removal efficiency decreased. Increasing of adsorption between $\mathrm{HA}$ and adsorbent can be explained by the chemical properties of HA. HA is composed of numerous polymeric ingredients

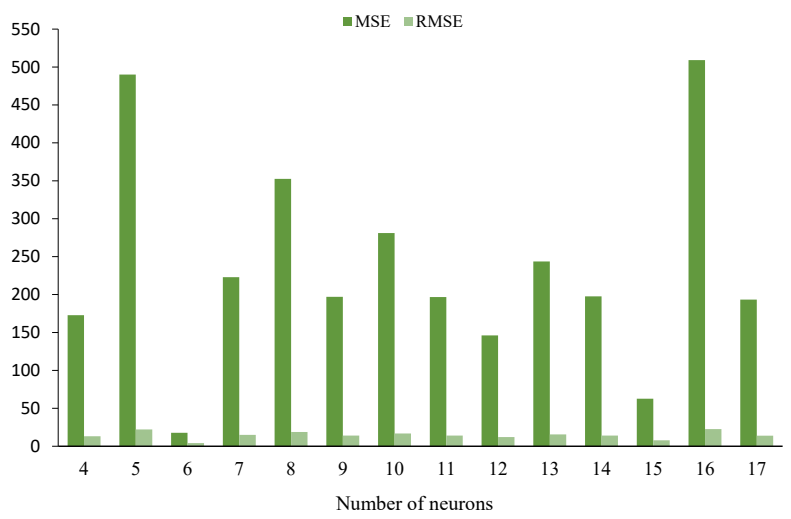

Figure 10. MSE and RMSE in the ANNs designed for determining the optimal number of neuron.

Training: $R=0.9121$
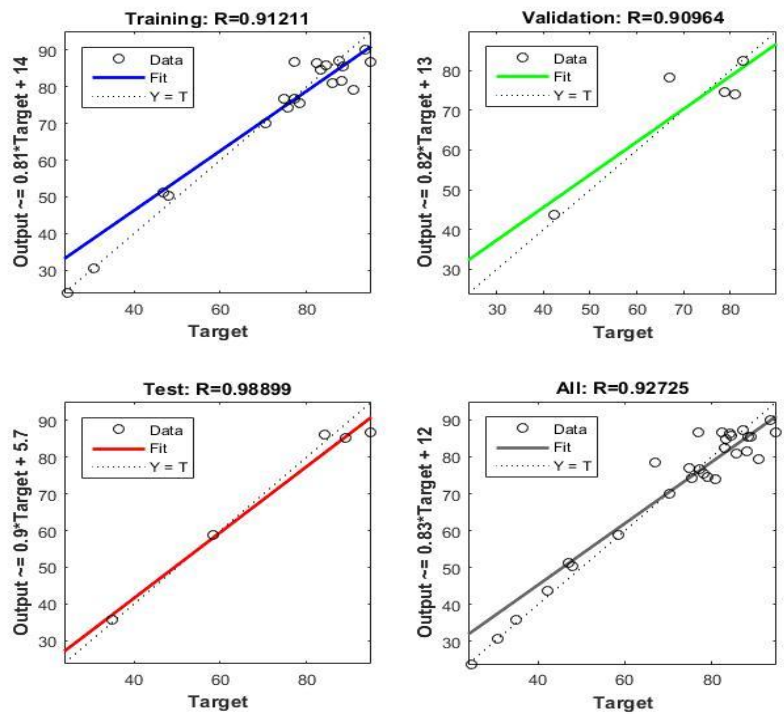

Figure 11. Neural network model with training, validation, test, and all prediction set. with main functional groups as carboxylic and phenolic groups $(3,39)$. These groups can be ionized at higher $\mathrm{pH}$ values to exhibit anionic characteristics. These anionic species will compete with hydroxyl in order to inhabit the active sites of the adsorbent that lead to the decreasing the HA adsorption (40). Also, due to the increasing increase of the electrostatic repulsion between the negative charge on the adsorbent surface and HA, the adsorption of HA gradually decreased as $\mathrm{pH}$ increased (10).

Imyim and Prapalimrungsi in their study on the removal of HA from water by aminopropyl- functionalized RHA found that the adsorption capacity of HA by this adsorbent increased with decreasing $\mathrm{pH}$ from 5 to 3 . The highest absorption rate of $\mathrm{HA}$ was obtained at $\mathrm{pH}$ 3-4 while at a $\mathrm{pH}$ higher than 5 , the adsorption capacity remained constant (15). Similar results have been reported for other adsorbents like activated carbon and bentonite $(41,42)$. Jarvis and Majewski investigated HA removal using plasma-polymerized allylamine coated with quartz particles. They found that with increasing $\mathrm{pH}$, the adsorption capacity of HA decreased. The maximum $\mathrm{HA}$ adsorption was obtained at $\mathrm{pH}=5$ (17).

At $\mathrm{pHs}$ higher than $\mathrm{pH}_{\mathrm{zpc}}$, negative species are predominant and the adsorbent surface will be negatively charged. However, at $\mathrm{pHs}$ lower than $\mathrm{pH}_{z p c}$, positive species are predominant and the adsorbent surface will be positively charged $(15,42,43)$.

\section{Effect of adsorbent dose}

The results indicated that with increasing the adsorbent dose, the removal efficiency of HA increased. This is due to the increase of the surface area and the availability of more binding sites for adsorption. At higher adsorbent doses, as the adsorbent dose increases, the contact area between the adsorbent and the adsorbate also increases, and subsequently, the removal efficiency increases (28).

The results also showed that the adsorption capacity decreased with increasing the adsorbent dose. This is due to the active sites of the adsorbent and the available specific surface area (26). Similar results about the effect of adsorbent dose on the HA removal efficiency were obtained for the other types of adsorbents $(44,45)$.

\section{Effect of contact time}

According to the results, the removal efficiency of HA increased with increasing the contact time. The increasing of the removal efficiency with time is due to the availability of a large number of vacant surface sites. In the present 
study, the adsorption of HA by shellfish ash reached equilibrium in 180 minutes. In a study by Imyim and Prapalimrungsi, the contact time required for reaching the adsorption equilibrium was reported to be 60 and 30 min for RHA and RHA- $\mathrm{NH}_{2}$, respectively (15). In another study by Zhao et al, the adsorption was very rapid so that after 2 hours, the adsorption reached equilibrium (1).

\section{Effect of humic acid initial concentration}

Based on the results, by increasing the HA initial concentration to $50 \mathrm{mg} / \mathrm{L}$, the adsorption capacity increased. This can be explained by the fact that the driving force for overcoming the transport resistance of HA from liquid phase to solid phase increased with increasing the initial concentration to $50 \mathrm{mg} / \mathrm{L}$. At higher concentrations, this issue was not effective for adsorption because at higher concentrations, the limitations of available surface will prevent suitable adsorption and the increasing of the driving force is negligible (46).

Jarvis and Majewski stated that the reason for increasing the HA absorption with increasing the HA initial concentration is that the increase of the HA initial concentration leads to an increase in the driving force, and subsequently, the saturation of the adsorption active sites located on the adsorbent surface by the pollutant (17), which is consistent with the results of studies by Imyim and Prapalimrungsi and Wang et al. They reported that with increasing the pollutant initial concentration, adsorption also increased $(15,16)$.

\section{Adsorption isotherms}

The applicability of isotherm equations is compared by judging the correlation coefficient $\left(\mathrm{R}^{2}\right)$. The results showed that the Langmuir isotherm $\left(\mathrm{R}^{2}>0.9\right)$ was fitted well with the experimental data in comparison with the Freundlich and Temkin isotherms for both concentrations. Also, the $R_{L}$ value obtained is less than 1 , indicating favorable adsorption of HA, which is consistent with the results reported by Wang et al. The $\mathrm{R}_{\mathrm{L}}$ value obtained in their study was between 0.040 and 0.429 , indicating that the $\mathrm{HA}$ adsorption on polyaniline/attapulgite composite was desirable (3). In a study by Zhan et al, the HA adsorption by cetylpyridinium bromide-modified zeolite followed the Langmuir isotherm. The regression coefficients were used as the fitting criteria to find out this isotherm (5), which is consistent with the results of the present study and those reported by Imyim and Prapalimrungsi. In their study on the HA adsorption on aminopropyl-functionalized RHA, it was found that the Langmuir isotherm was fitted well with the adsorption data (15).

\section{Adsorption kinetics}

Based on the results, the adsorption kinetic of HA followed the pseudo-second-order kinetic $\left(\mathrm{R}^{2}>0.99\right)$. Also, the obtained $\mathrm{q}_{e}$ values were closely fitted with the experimental data. Zhang et al investigated the HA adsorption using organo-layered double hydroxides. They reported that the pseudo-second-order kinetic was fitted well with the experimental data with high $\mathrm{R}^{2}$ value (47). Wan Ngah et al found that the adsorption of HA onto chitosan- $\mathrm{H}_{2} \mathrm{SO}_{4}$ beads followed the pseudo-second-order kinetics predominantly compared to the pseudo-firstorder kinetic (14). Similar results were also obtained by Rauthula and Srivastava (12), Tang et al (48), and Tsai et al (49).

\section{Artificial neural network modeling}

According to the results, the lowest mean squared error belonged to 6 neurons in the hidden layer of the neural network, which provides the highest performance and the lowest error for the network. Less dispersion of the predicted data around the regression line indicates the high accuracy of the model in estimating the data. Accordingly, the results presented in Figure 11 (training), indicate the efficiency of the selected neural network model. Comparison of the experimental results and those of the ANN model showed regression coefficient of 0.9273, indicating that the ANN model used can model the experimental results with a relatively good accuracy. Therefore, ANN can be used as a suitable method for modeling the absorption process.

\section{Conclusion}

Increasing health problems, management costs, and operational considerations for water treatment containing HA led to the use of new and cost-effective adsorbents derived from renewable resources. According to the results, aquatic-shell wastes such as shellfish ash are effective biosorbents for removal of HA from acidic waters. These natural wastes exist in large amounts and can be utilized as an alternative to existing commercial adsorbents with a cost-effective preparation method for removing HA. The results also showed that increasing of the adsorption dose and contact time led to an increase in the adsorption capacity and increasing of $\mathrm{pH}$ and $\mathrm{HA}$ initial concentration led to a decrease in the adsorption capacity. The equilibrium sorption data are fitted well with the Langmuir isotherm and followed the pseudosecond-order kinetic. Utilization of the shellfish ash as a biosorbent for removal of HA is a simple, effective, and economical method. The results indicate that the ANN model can be successfully applied to predict the behavior of HA adsorption process.

\section{Acknowledgments}

The funders were not involved in this research. The authors would like to gratitude Ahvaz Jundishapur University of Medical Sciences for granting the permission to perform the study.

Ethical issues

The authors hereby certify that all the data collected 
during the research are as expressed in the manuscript, and no data from the study has been or will be published elsewhere separately.

\section{Competing interests}

The authors declare that they have no conflict of interests.

\section{Authors' contributions}

All authors were involved in the study design, experiments, data collection and analysis, and manuscript preparation. The final version of the manuscript was reviewed and confirmed by all authors.

\section{References}

1. Zhao L, Luo F, Wasikiewicz JM, Mitomo H, Nagasawa N, Yagi T, et al. Adsorption of humic acid from aqueous solution onto irradiation-crosslinked carboxymethylchitosan. Bioresour Technol 2008; 99(6): 1911-7. doi: 10.1016/j. biortech.2007.03.030.

2. Oguz E, Tortum A, Keskinler B. Determination of the apparent rate constants of the degradation of humic substances by ozonation and modeling of the removal of humic substances from the aqueous solutions with neural network. J Hazard Mater 2008; 157(2-3): 455-63. doi: 10.1016/j.jhazmat.2008.01.018.

3. Wang J, Han X, Ma H, Ji Y, Bi L. Adsorptive removal of humic acid from aqueous solution on polyaniline/ attapulgite composite. Chem Eng J 2011; 173(1): 171-7. doi: 10.1016/j.cej.2011.07.065.

4. Karolczyk J, Mozia S, Morawski AW, Przepiórski J. Adsorption of humic acid on mesoporous carbons prepared from poly-(ethylene terephthalate) templated with magnesium compounds. Pol J Chem Technol 2012; 14(4): 95-9. doi: 10.2478/v10026-012-0109-y.

5. Zhan Y, Zhu Z, Lin J, Qiu Y, Zhao J. Removal of humic acid from aqueous solution by cetylpyridinium bromide modified zeolite. J Environ Sci (China) 2010; 22(9): 132734. doi: 10.1016/s1001-0742(09)60258-8.

6. Wang J, Wang XC. Ultrafiltration with in-line coagulation for the removal of natural humic acid and membrane fouling mechanism. J Environ Sci (China) 2006; 18(5): 8804. doi: 10.1016/s1001-0742(06)60008-9.

7. Uyguner CS, Suphandag SA, Kerc A, Bekbolet M. Evaluation of adsorption and coagulation characteristics of humic acids preceded by alternative advanced oxidation techniques. Desalination 2007; 210(1-3): 183-93. doi: 10.1016/j.desal.2006.05.043.

8. Hartono T, Wang S, Ma Q, Zhu Z. Layer structured graphite oxide as a novel adsorbent for humic acid removal from aqueous solution. J Colloid Interface Sci 2009; 333(1): 1149. doi: 10.1016/j.jcis.2009.02.005.

9. Lowe J, Hossain MM. Application of ultrafiltration membranes for removal of humic acid from drinking water. Desalination 2008; 218(1-3): 343-54. doi: 10.1016/j. desal.2007.02.030.

10. Wan Ngah WS, Hanafiah MA, Yong SS. Adsorption of humic acid from aqueous solutions on crosslinked chitosan-epichlorohydrin beads: kinetics and isotherm studies. Colloids Surf B Biointerfaces 2008; 65(1): 18-24. doi: 10.1016/j.colsurfb.2008.02.007.
11. Zhang $\mathrm{P}$, Wu Z, Zhang G, Zeng G, Zhang H, Li J, et al. Coagulation characteristics of polyaluminum chlorides PAC-Al30 on humic acid removal from water. Sep Purif Technol 2008; 63(3): 642-7. doi: 10.1016/j. seppur.2008.07.008.

12. Rauthula MS, Srivastava VC. Studies on adsorption/ desorption of nitrobenzene and humic acid onto/from activated carbon. Chem Eng J 2011; 168(1): 35-43. doi: 10.1016/j.cej.2010.12.026.

13. Peng X, Luan Z, Chen F, Tian B, Jia Z. Adsorption of humic acid onto pillared bentonite. Desalination 2005; 174(2): 135-43. doi: 10.1016/j.desal.2004.09.007.

14. Wan Ngah WS, Fatinathan S, Yosop NA. Isotherm and kinetic studies on the adsorption of humic acid onto chitosan-H2SO4 beads. Desalination 2011; 272(1-3): 293300. doi: 10.1016/j.desal.2011.01.024.

15. Imyim A, Prapalimrungsi E. Humic acids removal from water by aminopropyl functionalized rice husk ash. J Hazard Mater 2010; 184(1-3): 775-81. doi: 10.1016/j. jhazmat.2010.08.108.

16. Wang $\mathrm{S}$, Terdkiatburana T, Tadé MO. Adsorption of $\mathrm{Cu}(\mathrm{II})$ $\mathrm{Pb}(\mathrm{II})$ and humic acid on natural zeolite tuff in single and binary systems. Sep Purif Technol 2008; 62(1): 64-70. doi: 10.1016/j.seppur.2008.01.004.

17. Jarvis KL, Majewski P. Plasma polymerized allylamine coated quartz particles for humic acid removal. J Colloid Interface Sci 2012; 380(1): 150-8. doi: 10.1016/j. jcis.2012.05.002.

18. Yetilmezsoy K, Demirel S. Artificial neural network (ANN) approach for modeling of $\mathrm{Pb}(\mathrm{II})$ adsorption from aqueous solution by Antep pistachio (Pistacia vera L.) shells. J Hazard Mater 2008; 153(3): 1288-300. doi: 10.1016/j. jhazmat.2007.09.092.

19. Tanzifi M, Yaraki MT, Kiadehi AD, Hosseini SH, Olazar $\mathrm{M}$, Bharti AK, et al. Adsorption of Amido Black 10B from aqueous solution using polyaniline $/ \mathrm{SiO}(2)$ nanocomposite: experimental investigation and artificial neural network modeling. J Colloid Interface Sci 2018; 510: 246-61. doi: 10.1016/j.jcis.2017.09.055.

20. Haghiabi AH, Nasrolahi AH, Parsaie A. Water quality prediction using machine learning methods. Water Qual Res J 2018; 53(1): 3-13. doi: 10.2166/wqrj.2018.025.

21. Carsky M, Do DD. Neural network modeling of adsorption of binary vapour mixtures. Adsorption 1999; 5(3): 183-92. doi: 10.1023/a:1008977528474.

22. Bagheri M, Mirbagheri SA, Bagheri Z, Kamarkhani AM. Modeling and optimization of activated sludge bulking for a real wastewater treatment plant using hybrid artificial neural networks-genetic algorithm approach. Process Saf Environ Prot 2015; 95: 12-25. doi: 10.1016/j. psep.2015.02.008.

23. Ding YR, Cai YJ, Sun PD, Chen B. The use of combined neural networks and genetic algorithms for prediction of river water quality. J Appl Res Technol 2014; 12(3): 493-9. doi: 10.1016/s1665-6423(14)71629-3.

24. Ghaedi AM, Vafaei A. Applications of artificial neural networks for adsorption removal of dyes from aqueous solution: a review. Adv Colloid Interface Sci 2017; 245: 20 39. doi: 10.1016/j.cis.2017.04.015.

25. Yang Y, Wang G, Wang B, Li Z, Jia X, Zhou Q, et al. Biosorption of Acid Black 172 and Congo Red from 
aqueous solution by nonviable Penicillium YW 01: kinetic study, equilibrium isotherm and artificial neural network modeling. Bioresour Technol 2011; 102(2): 828-34. doi: 10.1016/j.biortech.2010.08.125.

26. Daifullah AAM, Girgis BS, Gad HMH. A study of the factors affecting the removal of humic acid by activated carbon prepared from biomass material. Colloids Surf A Physicochem Eng Asp 2004; 235(1-3): 1-10. doi: 10.1016/j. colsurfa.2003.12.020.

27. Wang S, Ma Q, Zhu ZH. Characteristics of unburned carbons and their application for humic acid removal from water. Fuel Process Technol 2009; 90(3): 375-80. doi: 10.1016/j.fuproc.2008.10.010.

28. Ghaneian MT, Jamshidi B, Dehvari M, Amrollahi M. Pomegranate seed powder as a new biosorbent of reactive red 198 dye from aqueous solutions: adsorption equilibrium and kinetic studies. Res Chem Intermed 2015; 41(5): 322334. doi: 10.1007/s11164-013-1427-2.

29. Zhang X, Bai R. Mechanisms and kinetics of humic acid adsorption onto chitosan-coated granules. J Colloid Interface Sci 2003; 264(1): 30-8. doi: 10.1016/s00219797(03)00393-x.

30. Anandkumar J, Mandal B. Adsorption of chromium(VI) and Rhodamine B by surface modified tannery waste: kinetic, mechanistic and thermodynamic studies. J Hazard Mater 2011; 186(2-3): 1088-96. doi: 10.1016/j. jhazmat.2010.11.104.

31. Ghaneian MT, Ehrampoush MH, Arany AM, Jamshidi B, Dehvari M. Equilibrium and kinetic studies of $\mathrm{Cr}(\mathrm{VI})$ removal from synthetic wastewater by Acroptilon repense flower powder. Pol J Chem Technol 2013; 15(2): 40-7. doi: 10.2478/pjct-2013-0022

32. Cimino G, Passerini A, Toscano G. Removal of toxic cations and $\mathrm{Cr}(\mathrm{VI})$ from aqueous solution by hazelnut shell. Water Res 2000; 34(11): 2955-62. doi: 10.1016/s00431354(00)00048-8.

33. Zhang H, Tang Y, Cai D, Liu X, Wang X, Huang Q, et al. Hexavalent chromium removal from aqueous solution by algal bloom residue derived activated carbon: equilibrium and kinetic studies. J Hazard Mater 2010; 181(1-3): 801-8. doi: 10.1016/j.jhazmat.2010.05.084.

34. Moussavi G, Talebi S, Farrokhi M, Sabouti RM. The investigation of mechanism, kinetic and isotherm of ammonia and humic acid co-adsorption onto natural zeolite. Chem Eng J 2011; 171(3): 1159-69. doi: 10.1016/j. cej.2011.05.016.

35. Ghaneian MT, Bhatnagar A, Ehrampoush MH, Amrollahi M, Jamshidi B, Dehvari M, et al. Biosorption of hexavalent chromium from aqueous solution onto pomegranate seeds: kinetic modeling studies. Int J Environ Sci Technol 2017; 14(2): 331-40. doi: 10.1007/s13762-016-1216-8.

36. Shanmugaprakash M, Sivakumar V. Development of experimental design approach and ANN-based models for determination of $\mathrm{Cr}(\mathrm{VI})$ ions uptake rate from aqueous solution onto the solid biodiesel waste residue. Bioresour Technol 2013; 148: 550-9. doi: 10.1016/j. biortech.2013.08.149.
37. Özdemir U, Özbay B, Veli S, Zor S. Modeling adsorption of sodium dodecyl benzene sulfonate (SDBS) onto polyaniline (PANI) by using multi linear regression and artificial neural networks. Chem Eng J 2011; 178: 183-90. doi: 10.1016/j. cej.2011.10.046.

38. Fatimah $\mathrm{S}$, Wiharto $\mathrm{W}$. The use of artificial neural network for modeling the decolourization of acid orange 7 solution of industrial by ozonation process. IOP Conference Series: Materials Science and Engineering. 2017; 172: 012052. doi: 10.1088/1757-899x/172/1/012052.

39. Li A, Zhao X, Liu H, Qu J. Characteristic transformation of humic acid during photoelectrocatalysis process and its subsequent disinfection byproduct formation potential. Water Res 2011; 45(18): 6131-40. doi: 10.1016/j. watres.2011.09.012.

40. Wang S, Zhu ZH. Humic acid adsorption on fly ash and its derived unburned carbon. J Colloid Interface Sci 2007; 315(1): 41-6. doi: 10.1016/j.jcis.2007.06.034.

41. Anirudhan TS, Suchithra PS. Adsorption characteristics of humic acid-immobilized amine modified polyacrylamide/ bentonite composite for cationic dyesin aqueous solutions. J Environ Sci 2009; 21(7): 884-91. doi: 10.1016/s10010742(08)62358-x.

42. Radian A, Carmeli M, Zadaka-Amir D, Nir S, Wakshal E, Mishael YG. Enhanced removal of humic acid from water by micelle-montmorillonite composites: comparison to granulated activated carbon. Appl Clay Sci 2011; 54(3-4): 258-63. doi: 10.1016/j.clay.2011.09.008.

43. Anirudhan TS, Ramachandran M. Surfactant-modified bentonite as adsorbent for the removal of humic acid from wastewaters. Appl Clay Sci 2007; 35(3-4): 276-81. doi: 10.1016/j.clay.2006.09.009.

44. Bai R, Zhang X. Polypyrrole-coated granules for humic acid removal. J Colloid Interface Sci 2001; 243(1): 52-60. doi: 10.1006/jcis.2001.7843.

45. Doulia D, Leodopoulos C, Gimouhopoulos K, Rigas F. Adsorption of humic acid on acid-activated Greek bentonite. J Colloid Interface Sci 2009; 340(2): 131-41. doi: 10.1016/j.jcis.2009.07.028.

46. Long Z, Wasikiewicz JM, Mitomo H, Nagasawa N, Yoshii F. Preparation and adsorption behavior for metal ions and humic acid of chitosan derivatives crosslinked by irradiation. Nucl Sci Tech 2007; 18(1): 42-9. doi: 10.1016/ s1001-8042(07)60017-7.

47. Zhang G, Wu T, Li Y, Huang X, Wang Y, Wang G. Sorption of humic acid to organo layered double hydroxides in aqueous solution. Chem Eng J 2012; 191: 306-13. doi: 10.1016/j.cej.2012.03.020.

48. Tang Y, Liang S, Yu S, Gao N, Zhang J, Guo H, et al. Enhanced adsorption of humic acid on amine functionalized magnetic mesoporous composite microspheres. Colloids Surf A Physicochem Eng Asp 2012; 406: 61-7. doi: 10.1016/j. colsurfa.2012.04.050.

49. Tsai WT, Chen HR, Kuo KC, Lai CY, Su TC, Chang YM, et al. The adsorption of methylene blue from aqueous solution using waste aquacultural shell powders. J Environ Eng Manag 2009; 19(3): 165-72. 